\title{
Carmen Benedet: una galerista pionera en el circuito español de los años sesenta
}

\author{
Juan Carlos Aparicio Vega ${ }^{1}$
}

Recibido: 28 de febrero de 2018 / Aceptado: 21 de mayo de 2018

Resumen. El presente artículo se refiere a la trayectoria profesional de Carmen Benedet, quien fundó en 1964 una galería de arte contemporáneo en la trastienda del negocio familiar, en pleno centro de Oviedo. La apertura tuvo lugar tras un concienzudo período de aprendizaje en contacto con varios negocios madrileños (Abril y Nebli), si bien su verdadera evolución transcurrió a partir de su estrecha y permanente relación con Juana Mordó y también de otros intermediarios del comercio artístico español (Gaspar, Maeght y Grupo Quince), entre los que se insertó con absoluta naturalidad pese a su posición periférica. Su concepto de galería, radicalmente moderno, sorprendió por su coherencia y apuesta por las últimas tendencias, en particular, las informalistas, que reflejó como si se tratase de una sala madrileña.

Palabras clave: Galería de arte; Oviedo; Informalismo; circuito artístico; Benedet; pionera.

\section{[en] Carmen Benedet: The Case of a Pioneer Art Gallerist in the Spanish Art Circuit of the 1960s}

\begin{abstract}
This paper addresses the career of Carmen Benedet, who in 1964 established an art gallery dedicated to contemporary art in the back shop of her family's business, in the very centre of Oviedo. The opening took place after a period of thorough training in contact with several Madrid businesses (Abril and Nebli), even though her true development would come about out of her close and permanent contact with Juana Mordó, as well as with several other intermediaries of the Spanish artistic commerce (Gaspar, Maeght, and Grupo Quince), a circle in which she inserted herself in an absolutely natural way, despite her peripheral location. Her radically modern gallery concept surprised everyone with her coherence and her bet on the latest tendencies, particularly the Art Informel ones, which she exhibited as if hers were a Madrid-based gallery.
\end{abstract}

Keywords: Art gallery; Oviedo; art Informel; art circuit; Benedet; pioneer.

Sumario. 1. Introducción. 2. La papelería de Heliodoro Benedet. 3. La apertura de la galería de arte. 4. El concepto de galería de Carmen Benedet. 5. El local expositivo. 6. La línea expositiva. 7. Publicaciones y acción cultural. El archivo de arte contemporáneo. 8. La red de relaciones profesionales de Benedet. 9. Relación con los medios. Comisiones de venta. Ferias de arte. 10.Conclusiones. 11. Fuentes documentales.

1 Departamento de Historia del Arte y Musicología. Universidad de Oviedo

apariciojuan@uniovi.es

Código ORCID: 0000-0002-0338-3743

Nuestro más sincero agradecimiento a Carmen Benedet, quien nos facilitó infinidad de informaciones acerca de su trabajo y del panorama galerístico español en que vivió y que protagonizó. También ha sido fundamental la ayuda del profesor Javier Barón, quien dirigió nuestra Tesis Doctoral, centrada precisamente en desentrañar ese olvidado y fundamental papel de las galerías de arte, especialmente complejo en sus momentos iniciales. Más informaciones al respecto en: Aparicio Vega, Juan Carlos (2015). Galerías de Arte en Asturias (1918-2005). Espacios y promotores (Tesis doctoral). Universidad de Oviedo, Oviedo. 
Cómo citar: Aparicio Vega, J. C. (2018) Carmen Benedet: una galerista pionera en el circuito español de los años sesenta, en Anales de Historia del Arte nº 28 (2018), 395-416.

\section{Introducción}

Las galerías de arte, que habían surgido como opción alternativa a los salones y exposiciones académicas, surgen con el cometido principal del fomento de la actividad artística, sin menoscabo de su imprescindible viabilidad económica, que en buena medida depende del perfil y conocimiento de sus promotores y del prestigio que éstos alcancen en su área de influencia.

En España el mercado del arte empezó a estructurarse a finales del siglo XIX. No se considera el papel de nuestro país, en ese sentido, central si se compara con las principales plazas europeas y esa perspectiva negativa, ya tradicionalmente asentada, ha restado brillo a algunos destacados marchands y a galerías de interés, últimamente sacadas a la luz a través de estudios científicos y exposiciones documentales. Sin embargo, Cataluña y, en particular, Barcelona fue un foco relativamente temprano ${ }^{2}$ donde se implantaron importantes galerías que en momentos puntuales reflejaron la modernidad casi de inmediato ${ }^{3}$. Este movimiento se vio empujado en aquel contexto debido al auge urbanístico y al surgimiento del ocio y el consumo cultural, que acrecentaron el interés de los coleccionistas. La nueva clase dominante precisaba de objetos de representación y para ello era imprescindible "una estructura más dinámica, flexible, con rotación más rápida y menos costosa, abierta al nuevo público burgués y al cambio de gusto: la galería"4.

Mientras, en Madrid ${ }^{5}$ el sistema del mercado del arte, y por tanto las galerías, se compondría de forma decidida inmediatamente después de la guerra civil. Así, sería en la posguerra ${ }^{6}$ cuando se organizasen tímidamente las primeras nuevas firmas que desempeñaron un papel trascendental en el devenir artístico del país, si bien el camino sería lento y el punto de partida era ciertamente "desalentador"

2 Véase Fontbona, F. (2007). De la Sala Parés al arte suburbial pasando por Els Quatre Gats. En Sala, T.M. (ed.), Barcelona 1900. Amsterdam: Van Gogh Museum / Fonds Mercador / Lunwerg Editores, 129.

3 La capital catalana acogió a la vanguardia parisina gracias al empeño de galeristas como Josep Dalmau en la segunda década del siglo pasado, llegando a su punto álgido cuando París se encontraba paralizada durante la I Guerra Mundial. Véase Rousseau, P. (2002). La Galería Dalmau. La introducción de la abstracción en Cataluña y la vanguardia parisina durante la Primera Guerra Mundial. En cat. exp. París-Barcelona. 1888-1937. París / Barcelona: Réunion des musées nationaux / Museu Picasso, 327.

4 Vidal Oliveras, J. (2012). Galerisme a Barcelona. 1877-2012. Descobrir, defensar, difondre l'art. Barcelona: Ayuntamiento de Barcelona y Art Barcelona Associació de galeries, 24.

5 Aún faltan estudios de conjunto y monografías que determinen definitivamente el verdadero papel de los establecimientos que funcionaron en la capital durante el siglo XIX y primeras décadas de la centuria siguiente.

6 Véase Mercader, L. (1997). La Galería Biosca (1940-1959). De cómo Barcelona exporta la idea de galería de arte. De cómo Madrid difunde el arte catalán. En Bru de Sala, X. (Dir.), cat. exp. Barcelona-Madrid. 1898-1998. Sintonías y Distancias. Barcelona: Institut d'Edicions de la Diputació de Barcelona / Centre de Cultura Contemporània de Barcelona, 207 y 208.

7 Fernández Polanco, A. (1988). Las Galerías de Arte en el Madrid de Postguerra: Su labor en la transformación del panorama artístico nacional. Villa de Madrid, 97-98, 6. 
vía a convocar la Exposición Nacional de Bellas Artes ${ }^{8}$ y, en general, esa década supone un "retorno al realismo académico y un rechazo al surrealismo y al cubismo", en contraposición con lo acontecido en el comienzo del período anterior, en que los artistas buscaban "contenidos de profundo calado", produciéndose el "giro semántico de toda una generación"10.

Finalmente, superadas las consecuencias de la guerra, el sistema de galerías español se desarrolló plenamente en la segunda mitad del siglo pasado, siendo determinantes las firmas operativas en Madrid durante los años sesenta y setenta, que extendieron su entusiasmo a todas las provincias españolas.

De este modo y ya respecto al ámbito geográfico de nuestro estudio, el periférico territorio asturiano, se pudieron contemplar desde al menos las últimas décadas del siglo XIX cuadros en los escaparates de los lujosos comercios que reflejaban un panorama mejorado gracias al desarrollo industrial y al aporte de capital indiano. Asimismo, tuvieron una gran repercusión las grandes exposiciones ${ }^{11}$ celebradas en 1915, 1916 y 1918 en Gijón y Oviedo.

La durísima contienda interrumpió el incipiente desarrollo de las actividades expositivas y comerciales, iniciado sobre todo veinte años antes. Los cambios en las estructuras políticas y socio-económicas y en las instituciones culturales fueron tan importantes que la situación empeoró notablemente y se mantuvo un ambiente muy empobrecido durante muchos años.

Pero pese a ese precoz arranque, la consolidación del sector y la apuesta decidida por reflejar en mayor medida las nuevas tendencias artísticas no tuvieron lugar en Asturias hasta los años cincuenta, período en que se generó un ambiente cultural renovado que derivaría en el surgimiento, al unísono en Gijón y Oviedo, de las dos primeras galerías en 1958 , que se vería reafirmado en $1964^{12}$ con otras dos propuestas. Ese camino se inició en esta segunda y definitiva etapa con mayor ímpetu e incluso anticipación en la vecina ciudad de Santander gracias a la puesta en marcha de la librería y galería Sur en el verano de 1952, a cargo del inquieto Manuel Arce ${ }^{13}$. Sin embargo, pocas de estas iniciativas situadas fuera ${ }^{14}$ de los más dinámicos focos ma-

8 Mercader, L. (1997). op. cit., 207.

Véase Reglamento de las Exposiciones Nacionales de Bellas Artes, Madrid, Dirección General de Bellas Artes del Ministerio de Educación Nacional, s.f. (1952?), pp. 3 (art. $1^{\circ}$ ) y 13-14 (art. 34), en A.H.A., Fondo Diputación Provincial, Expte. 2617/40, documento 52.

9 Sepúlveda Sauras, Mª I. (2005).Tradición y Modernidad: Arte en Zaragoza en la década de los años cincuenta. Zaragoza: ed. Prensas Universitarias de Zaragoza, 21.

10 Esa "generación" fue escindida por la guerra de forma casi irrecuperable y "el entorno cultural que había permitido el desarrollo del nuevo arte se disolvió". Véase Carmona, E. (2005). Las poéticas del arte nuevo y los círculos concéntricos de la Generación del 27. 1926-1931. En cat. exp. La pintura del 27. Madrid: Guillermo de Osma Galería, 20.

11 La actividad expositiva de carácter artístico "no se produjo hasta el inicio de la Gran Guerra". Véase Barón Thaidigsmann, J. (2001). Renovación Artística y Exposiciones Regionales en Asturias (1915-1934). En Cabañas Bravo, M. (Coord.), El Arte Español del Siglo XX. Su perspectiva al final del milenio. Madrid: Departamento de Historia del Arte del Instituto de Historia del Consejo Superior de Investigaciones Científicas, 205.

12 Casi al tiempo que el proyecto de Benedet, se desarrolla en un territorio igualmente periférico, Segovia, los hermanos Serrano abren La Casa del Siglo XV. Véase cat. exp. El Siglo XX en La Casa del Siglo XV. Una galería de arte en Segovia. 1963-2000. Segovia, Museo de Arte Contemporáneo Esteban Vicente, del 29 de abril al 5 de septiembre de 2004.

13 Huici, F. (1996). Rumbo Sur. En cat. exp. Galería Sur. Exposición documental. Plataformas de la Vanguardia en España. III. Madrid: Museo Nacional Centro de Arte Reina Sofía, 14.

14 Entre éstas sorprende por su temprana implantación la Galería Wiot, fundada en mayo de 1949 en Las Palmas. Véase García de Vegueta, L. (1974?). La Galería Wiot, pase a la historia, sin fuente. Archivo de El Museo Ca- 
drileño ${ }^{15}$ y catalán, tuvieron interés y aunque se abrían salas comerciales, el cambio cualitativo llegaría en muchas provincias al tiempo, justo al comenzar la década de los años setenta, momento en que surgieron nuevas propuestas de valiente apuesta por el arte actual también en la región asturiana que preludiarían un desarrollo generalizado y diversificado ${ }^{16}$.

Sin embargo, es claro que la falta de estudios de cierta profundidad sobre el sector en cada región o localidad hace que prevalezcan opiniones sesgadas y en no pocas ocasiones contrarias a la realidad. Esta circunstancia es trasladable al contexto asturiano, donde es ya tradicional la indiferencia, por desconocimiento, hacia la labor de muchos de estos agentes y promotores, situación alimentada por la ausencia o pérdida de material y fuentes adecuados con que reconstruir la historia de las galerías y sus promotores.

La recuperación parcial vino fundamentalmente en "la década de los años cincuenta y especialmente su segunda mitad fue muy fructífera para las artes plásticas españolas" y muchos artistas apostaron por una "necesaria renovación del arte" y "este nuevo arte tenía muy poco que ver con el de la Segunda República"17. Ello quedó bien reflejado tanto a través de artistas figurativos (también "renovadores y vanguardistas") como de los consabidos abstractos y además nuestras pioneras galerías reflejan ese salto cualitativo respecto a la paupérrima década anterior, en que a nivel nacional solamente destacaron las iniciativas de la Academia Breve de Pintura, la actividad de Dau al Set y la recordada Escuela de Altamira ${ }^{18}$. Igualmente, se dejó sentir en la región asturiana desde muy pronto la presencia de Antonio Suárez en el efímero pero influyente grupo El Paso (1957-1960), celebrándose en Oviedo la primera exposición del colectivo fuera de Madrid, hecho que provocó una enorme polémica.

Así, a continuación, trataremos de arrojar luz sobre la extracción social, formación, trayectoria e intereses de la galerista Carmen Benedet y cómo logró presentar desde su establecimiento propuestas actuales en un momento tan temprano para el caso español. Hablaremos del concepto de local elegido y de sus expositores, además de su particular forma de trabajar e interrelacionarse con el circuito existente y sobre todo con los agentes del comercio artístico.

nario, Fondo Documental Galería Wiot.

En Valladolid empieza a asentarse lentamente el comercio artístico sobre todo a partir de 1962, en que abren tres galerías. Véase Ortega Coca, M ${ }^{\mathrm{a}}$ T. (1980). La actividad artística en Valladolid (de 1950 a 1980). Valladolid: Servicio de Publicaciones de la Diputación Provincial de Valladolid, 42 y 87.

15 La precariedad del sector en los años cincuenta obligaba a diversificar los servicios de las galerías incluso en Madrid, donde Turner (Serrano, 5) aparte de la exhibición y venta de cuadros antiguos y modernos, esculturas, cerámicas, dibujos, grabados y libros, funcionaba como estudio-taller (proyectos de ambientación y decoración, pinturas murales, restauraciones de cuadros, esculturas, marfiles, abanicos, cerámica, etc., reproducciones de obras de arte) y se comercializaban muebles antiguos y modernos y libros de arte (españoles y extranjeros). Véase tarjeta Exposición Rubio Camín. Óleos, Madrid, Salas Turner, desde el 4 de febrero de 1953.

Ninguna galería de arte asturiana proporcionaba tal cantidad de prestaciones y el hecho de que esta sala ofreciese tantos servicios obedece al hecho de que especializarse era muy arriesgado en este tiempo.

16 "En torno a 1970 ya se daba en Asturias un ambiente propicio al desarrollo de una arte de vanguardia". Véase Barón Thaidigsmann, J. (1983). Reseña de las exposiciones de artistas asturianos en 1983. En Liño, 4, 929-935.

17 Llorente Hernández, Á. (2007). Una década de revolución plástica. Paralelismos, divergencias y tangencias entre la abstracción y la figuración en la década de los cincuenta. En cat. exp. Arte español de los cincuenta. Una década de revolución plástica. Madrid: Guillermo de Osma Galería, 3

$18 \quad$ Ibídem, 4 y 9. 


\section{La papelería de Heliodoro Benedet.}

El nombre del establecimiento está relacionado con el titular de la papelería familiar en que se alojó la galería cuatro décadas más tarde. En $1923{ }^{19}$ el padre de la galerista, Heliodoro Benedet Fernández ${ }^{20}$, inició su trabajo como gerente de una tienda perteneciente a la Sociedad Española de Papelería (S.E.P.), en cuya red nacional estaba incluida. El local comercial, alquilado, se encontraba en la planta baja del inmueble número $37^{21}$ de la calle Argüelles de Oviedo. Antes de obtener la concesión, Benedet ejerció como representante comercial de muebles de importación para la firma norteamericana Steel y vendía material topográfico también proveniente del extranjero.

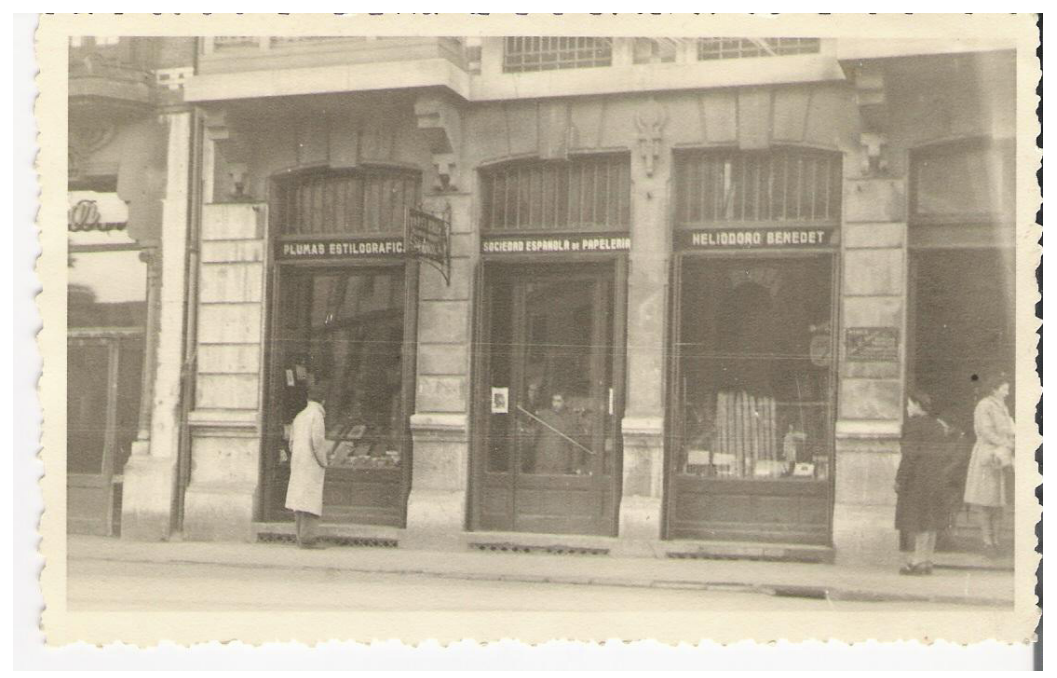

Figura 1. Fachada de la Papelería Benedet, s.f. Archivo de Carmen Benedet, Oviedo.

El domicilio de la Sociedad Española de Papelería estuvo en San Sebastián, íntimamente ligado a la Casa Nerecan ${ }^{22}$, cuya actividad vinculada al negocio de la impresión, permaneció hasta fechas recientes (2002) en aquella ciudad. Nerecan ${ }^{23}$ comercializaba objetos de escritorio y además en sus escaparates de la Avenida de

19 Información aportada por Carmen Benedet durante la entrevista mantenida en Oviedo el 18 de diciembre de 2004.

20 Heliodoro Benedet (Oviedo, 1885-1968) fue un comerciante de origen oscense instalado en Oviedo, donde nace, y casado con Margarita Álvarez Boves (Ramallo, Argentina, 1903-Oviedo, 2001). Regentó la papelería homónima durante más de cuarenta años; por otra parte, era aficionado al arte y llegó a vender escayolas realizadas a partir de reproducciones escultóricas de obras maestras del Museo del Prado con el objeto de proporcionar modelos a los artistas locales durante su formación académica.

21 Hernández, J. (1925). Guía de Oviedo. Año de 1925, Ávila, 370.

22 Información facilitada por Pili Azcarate Garitano, responsable del Archivo Municipal de Bergara (Guipúzcoa) el 19 de agosto de 2008.

23 El 21 de septiembre de 1920, Francisco Nerecan solicitó la apertura de su establecimiento.

Nerecan Hermanos C.R.C. «Casa Nerecan» tenía sede en el número 19 de la Avenida España y era una papelería y establecimiento de venta de materiales de bellas artes. Información corroborada por los responsables del Archivo General de Guipuzkoa el 2 de septiembre de 2008. La signatura del expediente del que procede la información es H-03178-38. 
la Libertad está documentada una importante actividad expositiva ${ }^{24}$. La red de sucursales se formó pronto, pues ya en $1911^{25}$ se publicitaban conjuntamente en catálogos comerciales. Por tanto, la Sociedad gestionaba un amplio número de tiendas, pero entró en crisis y los asociados vendieron las filiales. Margarita Álvarez Boves adquirió la sucursal ovetense al disolverse la empresa vasca en el año $1935^{26}$.De este modo, la galería nace arropada por un duradero y asentado negocio familiar [Fig.1].

Durante la primera etapa del establecimiento, llegó a funcionar una pequeña imprenta en la trastienda, vinculada a la referida sociedad papelera. Además, se vendieron libros, si bien la tienda se especializó desde el principio como papelería [Fig. 2].

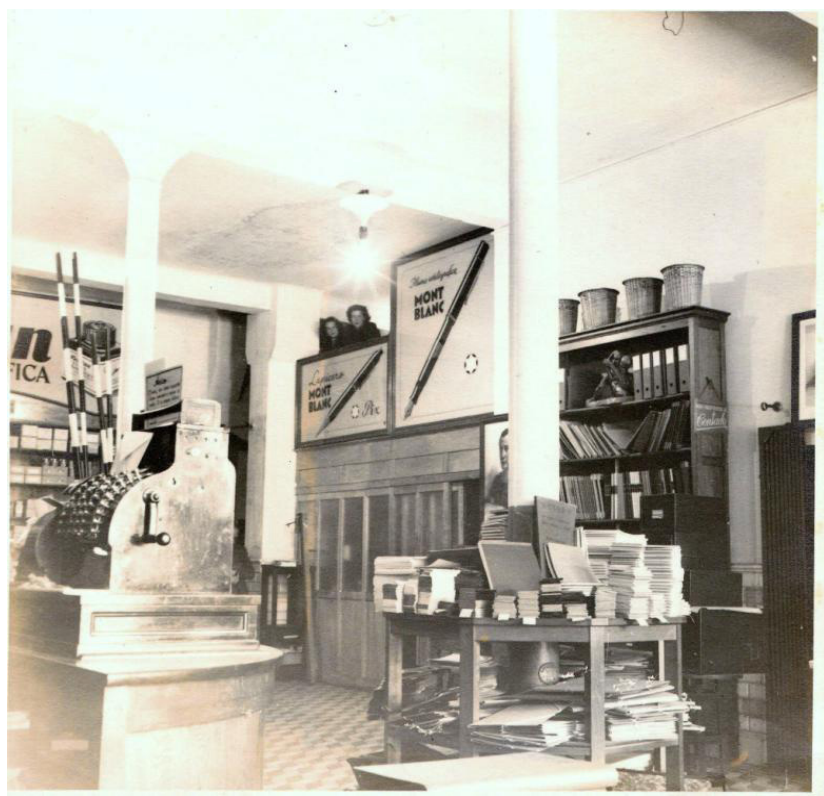

Figura 2. Interior de la Papelería Benedet, 1942. Archivo de Carmen Benedet, Oviedo.

\section{La apertura de la galería de arte.}

Ya a finales de la década de los años cuarenta la joven hija de los propietarios, Carmen Benedet Álvarez (Tuernes el Grande, Llanera, 1936) [Fig. 3], comenzó a trabajar en la papelería familiar que dirigiría definitivamente a partir del fallecimiento del fundador de la empresa en 1968.

24 En 1912 expusieron allí Elías Salavarría y José Machimbarrena. Véase García Marcos, J.A. (2007). Salas y Galerías de Arte en San Sebastián. 1878-2005. San Sebastián: Fundación Kutxa, 88.

25 Véase el Catálogo de Objetos de Escritorio, núm. 2, Sociedad Española de Papelería, San Sebastián, 1911.

26 La compra del negocio se formaliza el 20 de diciembre de 1935, según testimonio de C. Benedet durante la entrevista mantenida en el archivo el 18 de diciembre de 2004. Por tanto, la madre de la galerista ostentó en solitario la propiedad del negocio (incluida la galería de arte) a lo largo de su dilatada existencia y hasta su cierre en 1999. 


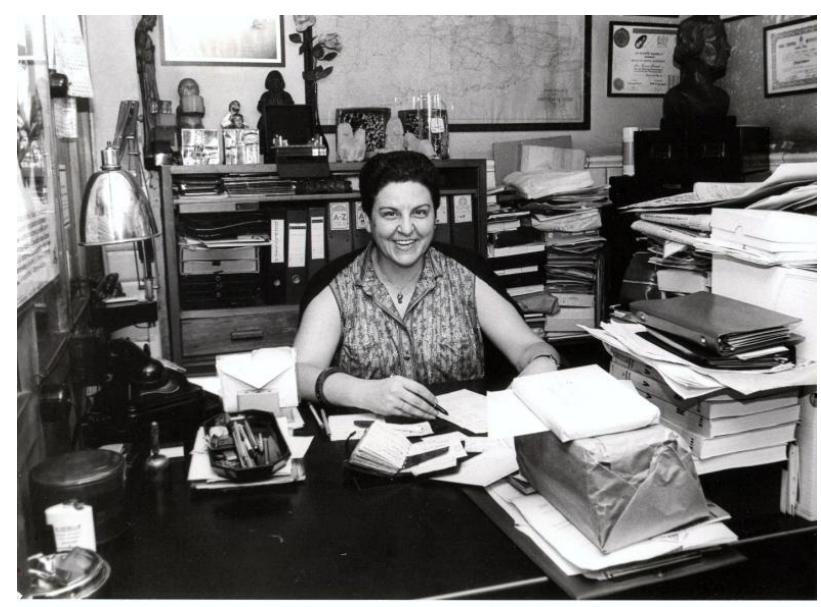

Figura 3. Carmen Benedet en su despacho de trabajo de la Papelería Benedet, 1985. Archivo de Carmen Benedet, Oviedo. Fotografía de Ana Müller.

La nueva galerista no solicitó licencia de apertura, pues dependía en todos los aspectos de la papelería en que estaba instalada. Los permanentes problemas de humedad del viejo inmueble ocasionaron que la apertura del local expositivo se retrasase tres meses. De este modo, la sala de arte comenzó a funcionar el 14 de septiembre de $1964^{27}$, cesando su actividad en diciembre de $1999^{28}$. Se trata, pues, de una de las empresas más longevas ${ }^{29}$ habidas en la historia del limitado mercado artístico asturiano.

La primera visita al Museo del Prado de Carmen Benedet durante un viaje de estudios fue «definitiva» en sus propósitos ${ }^{30}$. Al iniciarse la década de los años sesenta, frecuentó algunas de las pocas galerías de arte existentes en Madrid con el objeto de prepararse. La joven asturiana permaneció en la capital española en períodos alternos formándose para ejercitar años después la profesión de galerista durante una etapa que se anticipó al espectacular auge de las galerías de arte en Madrid y en el resto de España que se desarrollaría a partir de 1970. Por tanto, Benedet se preparó para este nuevo oficio al tiempo que abrían o cobraban importancia las salas pioneras de Madrid.

27 En el otoño del año anterior se anunciaba el proyecto en la prensa local y se explicaba el concepto de galería que pretendía Carmen Benedet, cuya «idea es ofrecer a todos esos cientos de magníficos artistas sin posibles la oportunidad de darse a ofrecer sin arriesgar ni una sola peseta» y a cambio de una comisión fija por las ventas producidas. Véase Evaristo Arce, Será inaugurada próximamente una galería de arte para los artistas jóvenes y sin posibles, La Nueva España, Oviedo, 17 de octubre de 1963. Información procedente del Archivo Benedet, sobre de Joaquín Vaquero.

A pesar de la tradicionalmente publicada fecha del 15 de septiembre, en la prensa de ese mismo día se recoge la apertura del día anterior. Véase «Vaquero inauguró la sala Benedet», en La Voz de Asturias, Oviedo, 15 de septiembre de 1964. No obstante, la propia galerista llegó a publicitar la fecha del 15-9-64 en el tarjetón de la muestra de Pablo Serrano (1990), indicando que habían pasado ya 26 años y medio.

28 Véase la tarjeta de la exposición Ángela Paci. Cajas de luz e infografía, Oviedo, Galería Benedet, del 9 de noviembre al 9 de diciembre de 1999.

29 A pesar de haber programado cerca de 350 exposiciones, ninguna galería asturiana llegó a celebrar antes de 1999 medio millar de muestras, número alcanzado por empresas también periféricas de regiones próximas, como el caso de la galería santanderina Sur.

30 Blanca Álvarez, Carmen Benedet: La rosa del laberinto, Extra Domingo, La Nueva España, Oviedo, 19 de junio de 1987 , p. 31. 
Los precedentes más remotos en la comercialización de arte para Benedet están relacionados con las acuarelas de Victorio Manchón que vendió hacia 1958 en el establecimiento familiar. Otros pintores le dejaban obra para ofertarla a los clientes de la papelería. Ante estas primeras ventas, el artista Joaquín Vaquero Palacios incitó a Benedet a abrir una galería en la trastienda del negocio, al tiempo que ésta iniciaba su propia colección artística.

\section{El concepto de galería de Carmen Benedet.}

Carmen Benedet casi siempre siguió la misma línea y apostó fundamentalmente por la obra gráfica y por las corrientes informalistas, gracias a un concierto con la galería Juana Mordó, con la que tomó acuerdo verbal para traer exposiciones inéditas a Oviedo.

De este modo, a pesar de las modestas instalaciones con que contaba, hizo evolucionar el débil comercio artístico asturiano e instauró un concepto de galería moderno y muy bien definido. Benedet comenzó exponiendo pintura y acabó siendo una gran especialista en obra gráfica, dando salida a importantes cantidades de estampas merced a su amplia lista de contactos comerciales. Además, logró equilibrar en su sala de exposiciones temporales la presencia de artistas asturianos y foráneos, si bien éstos últimos predominaron también en el capítulo de ventas.

Uno de los rasgos que caracterizaron a esta galerista pionera es que no hubo en el negocio un relevo generacional, con lo que la empresa se extinguió con la persona responsable sobre la que recaía todo el peso. En Madrid Juana Mordó fue sustituida por Helga de Alvear ${ }^{31}$, pero ésta actualizó el discurso e hizo algo totalmente diferente. Por tanto, en el caso de Benedet ni hubo renovación ni se produjo tampoco un reemplazo, algo que sí observamos en otras salas asturianas, como Altamira, Amaga y Nogal, donde los hijos de sus fundadores pasaron a regentar el negocio familiar.

Una de las principales cualidades de esta galerista es lo metódico, riguroso y programado de su trabajo, aspecto que ya se aprecia durante su inicial etapa formativa.

Por tanto, el negocio de Carmen Benedet no era una galería en exclusiva, sino que formaba parte de una empresa de carácter mixto, compuesta por papeleríalibrería y comercio artístico. La nueva firma Benedet fue una empresa con varias ramificaciones. Además de fundarse como papelería (1923-1999), fue ampliada la sociedad como galería de arte (1964-1999). Por otra parte, se abrió una sección dedicada a librería esotérica ${ }^{32}$, activa durante los años ochenta. Y todo ello convivió con el importante archivo de arte contemporáneo (1960-2018).

Numerosos artistas plásticos locales ${ }^{33}$ adquirieron en la tienda abundantes materiales de trabajo, principalmente papeles y pinturas, además de los más variados

31 Helga de Alvear (Kira Nahe, Alemania, 1936) tomó el relevo de Juana Mordó a quien compró la firma y además de galerista, como viene siendo habitual, se convirtió en destacada coleccionista. Véase Lucas, A. (2005). Helga de Alvear. Descubrir el Arte, 75, p.12.

32 Comenzó a funcionar a partir de 1979, según información facilitada por Carmen Benedet el 17 de mayo de 2006.

33 El escultor José María Navascués (Madrid, 1934-Oviedo, 1979), muy relacionado con la galerista, fue uno de sus principales clientes. Ejecutó muchos de sus trabajos sobre papeles importados de extraordinaria calidad adquiridos en este negocio ovetense, donde se vendían materiales para artistas de tres calidades distintas: escolar, 
utensilios. Es muy probable que Heliodoro Benedet ya surtiera desde el principio a los pintores que trabajaban en la ciudad. No obstante, en esos mismos años veinte en que abrió la papelería, otros establecimientos ofertaban en Oviedo materiales de importación como los tubos de colores Rembrandt que llegaban a la capital asturiana desde la firma Talens \& Zoons, Soc. An. (Appeldoorn, Holanda) y que se podían comprar en la tienda de los señores García Zalona y Cía, situada desde al menos 1922 en el número 13 de la cercana calle de Fruela ${ }^{34}$. Así, en la tienda de Benedet se podían encontrar soportes para obra gráfica y dibujo, que eran habitualmente importados. Esta diversidad de funciones y productos de la tienda Benedet recuerda que firmas como el veterano negocio madrileño Macarrón S. $A^{35}$. se dedicaban desde hacía mucho tiempo a la venta de marcos y utensilios para pintores ${ }^{36}$.

Respecto al perfil profesional de Carmen Benedet es el de una comerciante cualificada, formada como Perito Mercantil, que se convirtió en galerista en Madrid en el momento en que se estaba conformando el primer grupo moderno de profesionales españoles del sector. No obstante, muchos de los principios que rigen su actividad fueron adquiridos en el negocio familiar.

La galería fue abierta tras una etapa intermitente de formación y trabajo en las salas madrileñas antes citadas, pero el riesgo al emprender esta nueva iniciativa fue relativo, ya que la sala de exposiciones se apoyó desde su mismo origen en la papelería. Se trata de la primera mujer promotora de un comercio artístico en Asturias.

La galerista ovetense logró economizar todos los gastos derivados de su actividad expositiva y comercial, aplicando este criterio a la instalación de la propia exposición, a la edición de tarjetones anunciadores, a la publicidad en la prensa escrita e incluso al horario de apertura del local.

Respecto a la estructura socio-económica del período en que se fundó la galería de arte, su propietaria se encontró con numerosas dificultades para sindicar el negocio, pues dicha categoría no estaba consignada, llegando a inscribirse finalmente en el colectivo de los vendedores de marcos, molduras y láminas. Ni siquiera la profesión se encontraba tipificada a efectos fiscales y sindicales ${ }^{37}$.

bellas artes y profesional. Toda su obra menos la madera tiene relación con la papelería que también le surtía de lienzos, pasteles, gubias para madera, pinceles especiales de oreja de marta para acuarela, pinceles de buey y para óleo. El pintor informalista Antonio Suárez también le compró material para pintar. Información facilitada por Carmen Benedet el 17 de mayo de 2006.

34 Véase la carta fechada el 8 de febrero de 1922 que el director de Talens \& Zoon dirige al pintor gijonés Manuel Medina Díaz recomendando la adquisición de dichos materiales. El documento se conserva en el Museo Casa Natal de Jovellanos [Fondo Medina Díaz] de Gijón.

35 Macarrón se fundó en 1895 como tienda orientada a la venta y fabricación de utensilios artísticos. Pronto, comercializó pintura, dibujo, grabado, escultura, etc., aparte de ofertar materiales para dibujo técnico y un completo catálogo de servicios como el embalaje y envío de obras de arte o el montaje de exposiciones y enmarcado de cuadros, tareas en las que también Carmen Benedet disponía de amplios conocimientos adquiridos durante su etapa de formación en las galerías madrileñas y, posteriormente, a partir de su vínculo con Juana Mordó. Macarrón contó también con una sala de exposiciones desde 1941, si bien se caracterizó por su apoyo a la pintura académica. Allí se expuso por vez primera desde la guerra la obra del pintor Benjamín Palencia (1944).Véanse: Fernández Polanco, A. (1988). op. cit., 11; Alarcó, P. (1991). Historia de las galerías de arte y de los espacios oficiales de exposiciones. En cat. exp. Del Surrealismo al Informalismo. Arte de los años 50 en Madrid. Madrid: Comunidad de Madrid, 204 y 218; Calvo Serraller, F. (1992). Enciclopedia del arte español del Siglo XX. 2. El Contexto. Madrid: Mondadori, 269.

36 Fernández Polanco, A. (1988). op. cit., 8.

37 En esta época, el sector laboral español estaba organizado según una estructura de sindicatos verticales que obligaba a inscribir obligatoriamente toda actividad profesional en función de unas categorías determinadas. 


\section{El local expositivo}

Ulpiano Muñoz Zapata (1841- 1921) ${ }^{38}$ ideó en 1917 el inmueble donde se encontraba la tienda a iniciativa de Rafael Plana Marqués ${ }^{39}$. El solar resultó del derribo de la antigua cárcel de mujeres de la ciudad, la Galera. Las proporcionadas edificaciones que flanquean nuestra casa serían firmadas en esas fechas y posteriores por el arquitecto Manuel del Busto y Delgado (1879-1948) ${ }^{40}$.

No se llegó a realizar un plano de diseño del espacio expositivo, pero Joaquín Vaquero Palacios (Oviedo, 1900- Madrid, 1998) fue el arquitecto que se ocupó de su traza ${ }^{41}$ y además asesoró a su promotora en todo lo que afectaba a la instalación de la sala, que hubo de impermeabilizarse recubriendo las paredes con madera y luego a su vez con «sacos teñidos de color gris» ${ }^{42}$. En ese momento, ya existían en Oviedo dos modernos espacios en pleno funcionamiento en el centro de la ciudad, uno institucional (Caja de Ahorros de Asturias) y otro comercial (Cristamol).

El local ocupaba el espacio que en 1919 el propietario del inmueble, Rafael Plana Marqués, había dedicado a instalar una pequeña fábrica de chocolates ${ }^{43}$ y describía una amplia pieza rectangular a la que se añadía un cubículo cuadrado en la parte derecha. La trastienda de Benedet era un discreto hueco que describía una forma también rectangular, carente de luz natural y que contaba con un total de 32 metros cuadrados.

La presencia de la papelería determinó que la galería de arte ocupase un lugar secundario en el establecimiento y además le confirió un espacio poco afortunado, oculto tras la tienda. La galería es realmente una trastienda del negocio anterior, a pesar de los oportunos e improvisados consejos del ya renombrado arquitecto Vaquero conducentes a definir el local expositivo, que ayudó a configurar e iluminar.

Junto a la sala de exposiciones estaba el despacho ${ }^{44}$ de trabajo de la propiedad, con una superficie de aproximadamente 15 metros cuadrados, donde se ubicaba también el incipiente archivo de arte. La galería estaba separada de la tienda por una estantería.

Para hacer visible la galería de arte dentro de la tienda, era necesario el mueble expositor que a modo de vitrina fue colocado junto a la puerta de acceso a la pape-

38 A.M.O., Expte. Doc. 13.926. El edificio ha sido sometido recientemente a una profunda rehabilitación.

39 A.M.O., Exptes. 1, 1, 4,73 y 1,1, 4, 74.

40 Véanse referencias a estas construcciones en AA.VV (1998). Guía de Arquitectura y Urbanismo de la ciudad de Oviedo. Oviedo: Colegio Oficial de Arquitectos de Asturias, 126.

41 Rodríguez, R. (1996). Evocación de dos décadas. En cat. exp. Pintores Asturianos nacidos en las décadas 40 y 50. Oviedo: Consejería de Cultura del Principado de Asturias, 89.

Joaquín Vaquero tenía su residencia ovetense en esos años muy cerca de la papelería, en el sexto piso del número 8 de la calle Argüelles de Oviedo. Información procedente del Archivo Benedet, sobre de Joaquín Vaquero. La implicación de Vaquero en el proyecto espacial de la sala quedó recogida por la prensa de la época, cuya idea inicial se remonta a «cerca de dos años» antes. Véase Manuel Perujo, En una escombrera, rodeada de tuberías y bajo la claraboya, La Voz de Avilés, Avilés, 17 de septiembre de 1964.

42 Ibídem.

43 A.M.O., Expte. 1,1,4,76. La fábrica ya existía mucho antes, pues en 1902 la Compañia Asturiana de Artes Gráficas diseñó una envuelta para la misma. Véase Díaz González, Mª del M. (2004). Asturias litografiada. El comercio y la industria en imágenes (1900-1970).Gijón: Trea, 89 y 112 il.

44 Sobre el despacho existía un pequeño altillo con su misma superficie donde estaba instalado el taller de plumas estilográficas de la tienda y una pequeña zona de descanso para la propiedad. Además, la papelería contaba con un sótano, de problemática conservación, y un aseo. Por último, la tienda se comunicaba con un pequeño patio de manzana. 
lería e informaba de la programación de la sala. En la caja-vitrina ${ }^{45}$, diseñada por la galerista, se anunciaban las exposiciones. Estaba ejecutada en acero e incorporaba luz eléctrica.

El ingreso a la sala de exposiciones exigía atravesar toda la tienda, sujetas ambas al horario ${ }^{46}$ habitual de un comercio.

Los muebles de la tienda estaban fabricados en madera de haya importada. La S.E.P. regaló todo el mobiliario a sus sucursales, que eran todas iguales, pues contaban con los mismos anaqueles y muebles de madera hechos a medida para contener los productos de venta (papel, lápices o sobres).

Entre las particularidades del establecimiento regentado por la familia Benedet, destaca la existencia de un cartel de la casa Pelikán ${ }^{47}$, ejecutado al temple sobre tela, así como numerosos elementos vinculados a las estilográficas, uno de sus productos principales.

Las paredes de la sala [Fig. 4] se recubrieron con táblex ${ }^{48}$ marrón, luego pintado (se colocó encima un saco-arpillera teñido de gris elegido por Joaquín Vaquero) y bajo éstas, se encontraba separado mediante cámara de aire el alicatado blanco ya referido.

Para nivelar el suelo se puso cemento y se cubrió con una moqueta, siendo la primera de esparto y gris oscura, sustituida luego por otra de tonalidad verde también oscuro. Finalmente ya en la década de los años noventa la moqueta fue reemplazada definitivamente por un pavimento cerámico gris.
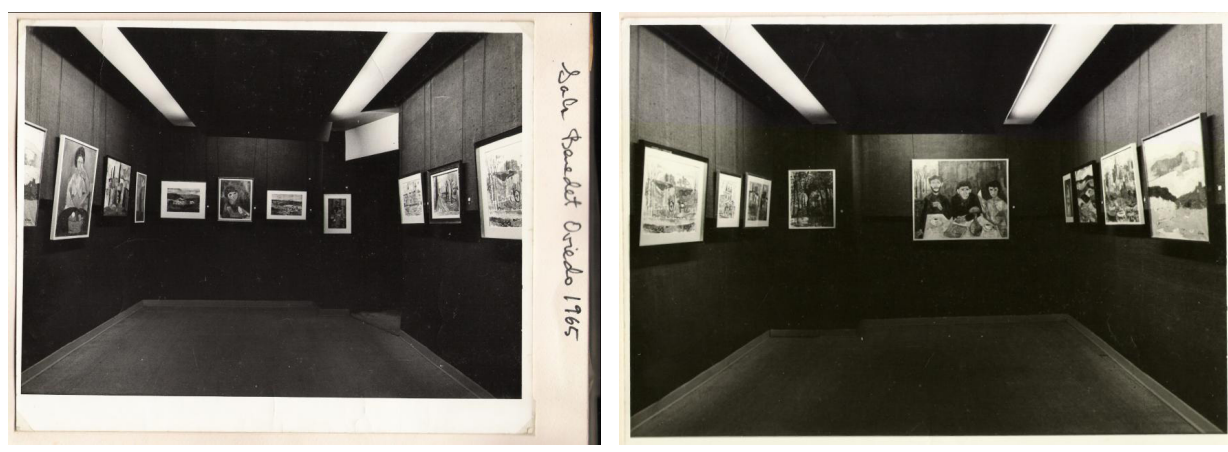

Figura 4. Vistas del interior de la sala Benedet en 1965 durante la exposición de María Teresa Díaz Gallego. Se aprecian las paredes del reducido espacio, diseñado por Joaquín Vaquero, totalmente enteladas así como el suelo enmoquetado y los primitivos y modernos sistemas de iluminación. Fuente: Álbum de María Teresa Díaz Gallego, Archivo gráfico del Museo Casa Natal de Jovellanos (Gijón).

45 A.M.O., Expte. B-2377/64. Con fecha de 10 de octubre de 1964, existe un documento manuscrito en que se refiere la instalación de una vitrina en la pared exterior de la calle Argüelles, en el negocio de D. Heliodoro Benedet Fernández. La caja tenía unas medidas de 0’68 x 0’47 m.

46 Carmen Benedet ajustaba el horario de su comercio a través de la realización de precarios estudios estadísticos de los visitantes de la galería. Ibídem.

47 La casa Pelikán (Alemania) se ocupó de amueblar las tiendas de la Sociedad Española de Papelería. Algunos de los muebles los conserva Carmen Benedet en la nueva sede de su archivo de arte.

48 Debido a las inundaciones que sufrió el establecimiento se cambió el táblex por melamina blanca. 
El techo fue rebajado dos metros gracias al empleo de escayola. En cuanto al sistema de colgado, se instalaron rieles de los que pendían bastones de diferentes tamaños. El segundo mecanismo colocado sustituyó al primero de raíles ${ }^{49}$ y consistía en un zócalo que recorría perimetralmente el techo; además, se incorporaron barrotes de madera incrustados en la pared con ganchos entre los que se estableció una separación cada diez centímetros. Esto se completaba con un cordón de calidad para colgar los cuadros y cuyo tejido era del mismo color que la pared. De este modo, el cuadro, suspendido de tiras de cuerdas de colores, siempre permanecía vertical y era muy cómodo y rápido colgar y desmontar cualquier exposición. El referido cordón de hilo de colores pendía de ganchos que quedaban ocultos tras el zócalo que bordeaba el techo.

Fuera del espacio expositivo propiamente dicho, en la parte derecha del pasillo de acceso al mismo, había una vitrina alargada con forma de triángulo escaleno ${ }^{50}$ en que la galerista solía colocar obra de pequeño formato.

El primer proyecto de iluminación con que contó el espacio expositivo era el tradicional de raíles con focos. Posteriormente, Vaquero sugirió que la galerista adquiriese los tubos de luz 57 de la firma Philips, que procuraban una luz muy similar a la natural. El arquitecto ovetense encargó las lámparas a esa empresa radicada en Holanda a través de Hidroeléctrica del Cantábrico. Tras dejar de fabricarse este modelo se instaló otro tipo tubo, más caro e importado de Estados Unidos ${ }^{51}$ que confería una luz uniforme y muy blanca. Los portalámparas eran articulados, permitiendo de este modo una rotación total, lo que era muy útil para iluminar escultura.

\section{La línea expositiva}

La galerista presentó objetos muy diversos a pesar de las evidentes limitaciones espaciales que hacían complicada la exhibición de algo que no fuera pintura de mediano o pequeño formato. De este modo, Benedet programó principalmente exposiciones de pintura, escultura y obra gráfica. Ocasionalmente, el local estuvo ocupado por cerámicas tapices y alfombras.

En cuanto a la política expositiva, Carmen Benedet llegó a alternar la obra de un artista de vanguardia con el trabajo de un creador asturiano consagrado y, por último, con la presentación de una joven promesa. Así, se aseguraban las ventas al tiempo que se dinamizaba el circuito. No obstante, el discurso expositivo estaba bien orientado hacia el arte contemporáneo.

Siempre se colocaba en un lugar bien visible de la sala el currículum artístico del expositor, que, en contadas ocasiones, era adjuntado al tarjetón.

Juana Mordó mandaba exposiciones a Oviedo, con lo que Benedet tenía dos listas, una proporcionada por la galerista madrileña y otra con artistas de la región por si le fallaba la primera. Cada vez que la sala no mostraba una exposición individual, se publicaba un cartel repleto de nombres de artistas nacionales y asturianos bajo el

\footnotetext{
49 Este definitivo sistema de colgado fue visto hacia 1965 por Carmen Benedet en una galería belga.

50 El expositor que anticipaba la sala de exposiciones estaba hecho en metacrilato y se componía de un cristal inclinado que se apoyaba en la pared y a su vez estaba sujeto a una base blanca en su parte inferior.

51 Este mismo tubo fue instalado por los responsables de la galería Maeght de Barcelona. Ibídem.
} 
título de Obra en permanencia ${ }^{52}$. Aparte de las exposiciones monográficas, se programaban normalmente dos colectivas por año a partir del nutrido y continuamente enriquecido fondo de la galería.

Al principio en la sala no se podía ver ni adquirir mucha obra gráfica y se vendía principalmente pintura. La estampa ingresó de forma definitiva en la galería a partir de la década de 1970, sobre todo gracias a la apertura de la empresa Grupo Quince [Fig. 5] en Madrid. La asturiana se dedicó plenamente al grabado desde 1975, si bien nunca llegó a editarlo. Maeght ${ }^{53}$ (Barcelona) le surtía también de libros de arte y de grabado y Gaspar $^{54}$ le suministraba estampas. Por tanto, Carmen Benedet no se ocupó de la obra gráfica hasta que no se asentaron definitivamente las grandes estructuras en Madrid y Barcelona que pudieran abastecer a la ovetense de trabajos de calidad.

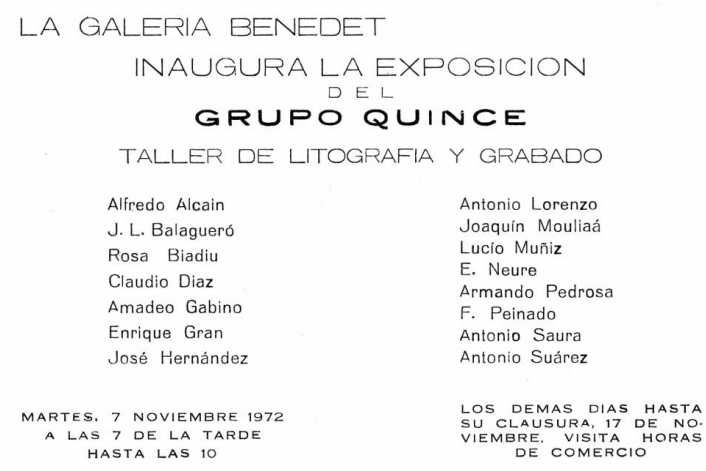

Figura 5. Tarjeta de la Exposición del Grupo Quince. Taller de Litografia y Grabado, Oviedo, Galería Benedet, del 7 al 17 de noviembre de 1972. Archivo del autor.

La relación con Grupo Quince ${ }^{55}$ se desarrolló desde que se fundó la empresa hasta su cierre. Los grabadores que integraban esta sociedad se quedaban las pruebas de artista y las pruebas de estado, el resto era totalmente comercializado. $\mathrm{Su}$ ingente producción era depositada en muchas galerías distribuidas por todo el país. Editaron carpetas de gran calidad y con muy buena presentación y diseño. Benedet se convirtió en uno de sus principales cauces comerciales ${ }^{56}$. En la

52 A modo de ejemplo véase la hoja suelta y el tarjetón titulados Exposición de Obras en permanencia, Oviedo, Galería Benedet, del 18 de junio al 28 de septiembre de 1974.

53 La sede parisina de la galería, fundada por Aimé (1906-1981) y Marguerite Maeght, se inauguró en 1945 con una muestra de Henri Matisse. En 1974 se crea la tienda barcelonesa. Véanse: Calvo Serraller, F. (1992). op. cit., 270; J.F. Yvars, El amigo de París, La Vanguardia, Barcelona, 22 de febrero de 2009, p. 48.

54 Gracias a la colaboración del marchand catalán Joan Gaspar, se presentó en Oviedo obra de Picasso, cedida para su exhibición y venta. La muestra número 200 de Benedet estuvo dedicada exclusivamente a Picasso.

55 Información de Javier Barón (Madrid, 13 de marzo de 2006).

56 Grupo Quince estaba dirigido hasta 1980 por María de Corral López-Dóriga (Madrid, 1940), cuyo padre, el santanderino Santiago de Corral era coleccionista de pintura.

Este grupo de profesionales aficionados al arte, fundado en 1971 con el objetivo de defender el grabado como manifestación artística con personalidad propia, contó con el pintor Antonio de Lorenzo como supervisor técnico del taller. Manuel Repila, litógrafo, se encargaba de las estampaciones en una prensa manual. La fundación 
galería asturiana se vendieron cantidades industriales de obra gráfica a un precio muy asequible, que llegó a incluir la obra de Robert Smith ${ }^{57}$.Este taller editorial contó desde su constitución con la activa participación del crítico de arte y componente del Grupo Pórtico, José Ayllón, también asociado con Juana Mordó ${ }^{58}$. Además de las ventas continuas efectuadas durante mucho tiempo a partir de depósitos, ya en noviembre de 1972 Carmen Benedet programó una muestra de Grupo Quince ${ }^{59}$.

La galería celebró tres centenares y medio de exposiciones, tal y como reflejan las tarjetas editadas por Carmen Benedet, en las que daba cuenta del número que hacía la muestra en la trayectoria de la sala. Así, la exposición número 300 coincidió con el aniversario del año $30^{60}$, ya que la galerista ovetense programaba diez exhibiciones por año ${ }^{61}$.

Diferentes aniversarios de la sala fueron celebrados con la presentación del trabajo de artistas sobresalientes. La exposición conmemorativa de su décimo año de actividad estuvo dedicada al grupo El Paso ${ }^{62}$, del que Carmen Benedet vendió mucha obra a lo largo de décadas. En esta muestra de 1974, cedida por Juana Mordó, se liquidó todo el producto presentado y se presentó una obra de cada artista. Joan Miró protagonizó una significativa muestra en $1985^{63}$.

Joaquín Vaquero ${ }^{64}$ fue el artista encargado de iniciar el recorrido expositivo de la sala, que se abrió el 14 de septiembre de $1964^{65}$. La muestra, a pesar del prestigio del artista, evocaba aquella primera que muchos años antes había sido la presentación neoyorquina del artista asturiano, en una reducida habitación de modesta instalación ${ }^{66}$.

En los primeros años se presentaron de forma monográfica los trabajos de artistas asturianos como José Luis Castro, Antonio Suárez ${ }^{67}$, Adolfo Bartolomé,

de esta empresa-taller posibilitó que la gráfica alcanzase una enorme difusión. Véanse: Anales de Provincia Sala de Arte, León, marzo 1972-diciembre 1973, 1974, 109-110; Calvo Serraller, F. (1992). op. cit., $207-208$. Información ampliada por Javier Barón el 16 de mayo de 2006.

57 Información de Javier Barón (Madrid, 13 de marzo de 2006).

58 Véase Calvo Serraller, F. (1992). op. cit. 49.

59 Véase tarjeta exp. Grupo Quince. Taller de Litografia y Grabado, Oviedo, Galería Benedet, del 7 al 17 de noviembre de 1972 .

60 La exposición número 300 estuvo dedicada a Tàpies (Véase tarj. exp. Antoni Tàpies, Oviedo, Galería Benedet, del 18 de octubre al 25 de noviembre de 1994).

61 Esta idea de numerar las muestras la pudo tomar Carmen Benedet del Salón Cano, abierto en 1939 en el número 26 del Paseo del Prado. La galerista frecuentó durante muchos años todos los negocios de arte madrileños y llegó a relacionarse profesionalmente con algunos de los más prestigiosos.

En una tarjeta editada por el Salón Cano con motivo de una muestra individual de Ubaldo Cantos (1972), se informa de que se trata de la exposición número 522. [Fondo Antonio Martín, Centro de Documentación del Museo Casa Natal de Jovellanos, Gijón].

62 Cat. exp. Galería Benedet. $10^{\circ}$ aniversario. Exposición n. ${ }^{\circ}$ 100, Oviedo, Galería Benedet, del 1 al 19 de octubre de 1974.

63 Blanca Álvarez, op. cit., p. 31.

${ }_{64}$ Egaña Casariego, F. (2008). Vaquero. Gijón: Colegio de Aparejadores y Arquitectos Técnicos de Asturias / Trea, 199. Véase también Nicomedes Santos, La pintura de Joaquín Vaquero, La Voz de Avilés, Avilés, 16 de septiembre de 1964.

65 Véanse: Rubén Suárez, Vaquero. El 15 de septiembre se inaugura su exposición en Benedet. La Voz de Asturias, Oviedo, 2 de julio de 1964; Vaquero inauguró la Sala Benedet. La Voz de Asturias, Oviedo, 15 de septiembre de 1964. Información procedente del Archivo Benedet. Se presentaron 15 trabajos del artista.

66 Manuel Perujo, op. cit.

67 Véase tríptico exp. Pinturas y Dibujos. Antonio Suárez, Oviedo-Gijón, junio/julio de 1966.La muestra no podía tener lugar sin la colaboración de la galerista del gijonés, Juana Mordó. 
Eduardo Úrculo, Orlando Pelayo ${ }^{68}$, Miguel Ángel Lombardía, Nicanor Piñole ${ }^{69}$, Fernando Magdaleno y Pepa Osorio. Posteriormente cedió la representación de sus artistas más comerciales a otras galerías.

Durante los años sesenta se exhibió la obra de destacados artistas del circuito nacional como Juan Barjola ${ }^{70}$ y Álvaro Delgado ${ }^{71}$, entre otros muchos. No obstante, pronto, la galerista comercializó fundamentalmente a los artistas informalistas españoles, que se habían presentado públicamente en la galería de Karl Buchholz (Gotinga, 1902-Bogotá, 1992) ${ }^{72}$.

En la década de los años setenta, se enseñó la producción última de Bernardo Sanjurjo, Trinidad Fernández, Alejandro Mieres, Orlando Pelayo y Antonio Suárez, Legazpi y Camín, entre otros.

La exhibición de esculturas sonoras de François Baschet ${ }^{73}$, realizada en 1977, fue un gran éxito de público ${ }^{74} \mathrm{y}$ una de las más interesantes que programó Carmen Benedet.

Entre los expositores de los años ochenta, destacaron Antonio Saura ${ }^{75}$ y Viola ${ }^{76}$, éste en colaboración y simultaneidad con la galería Rayuela de Madrid, del que se presentó su producción más actual. Por otra parte, fue la primera sala asturiana en mostrar la obra de Rafael Canogar ${ }^{77}$ en 1983.

En la misma década aparte de Francisco Farreras, una de las citas más significativas estuvo protagonizada por Antoni Clavé ${ }^{78}$, con obra pictórica y gráfica.

A lo largo de la última década de actividad de Benedet el público asturiano pudo disfrutar de la obra escultórica de Pablo Serrano ${ }^{79}$ y Amadeo Gabino ${ }^{80}$, que expuso

68 Véanse: O. Pelayo, Oviedo, Galería Benedet, del 1 al 16 de octubre de 1968; O. Pelayo ilustra con Once Aguafuertes La vida del Lazarillo de Tormes, Oviedo, Galería Benedet, del 13 al 31 de enero de 1976 y el tarjetóninvitación a la presentación del libro Once sonetos de Francisco Quevedo ilustrados con 12 aguafuertes de Pelayo y editado por Ides et Calendes (Neuchatel-Suiza), Oviedo, Galería Benedet, del 14 de diciembre de 1971 al 5 de enero de 1972.

69 Véase tarjetón exp. Nicanor Piñole, Oviedo, Galería Benedet, del 5 al 15 de noviembre de 1968.

70 Información recogida en la web oficial del artista: http: //www.juanbarjola.org [Consulta: 14 de mayo de 2012]. La exposición de Benedet tuvo lugar en 1965.

71 Véase cat. exp. Álvaro Delgado. Pinturas.1990-1994, Oviedo, Caja de Asturias, 1994, p. 79. La muestra tuvo lugar en 1969.

72 Véase Calvo Serraller, F. (1992). op. cit., 140-141.

73 Véanse: dossier de la exposición Esculturas musicales de François Baschet conservado en la Biblioteca del Museo Reina Sofía, Material especial/5/Benedet; 1 cat. mano exp. Baschet. Esculturas musicales, Madrid, Galería Juana Mordó, del 13 de octubre al 6 de noviembre de 1976.

74 Datos obtenidos durante la entrevista mantenida con Carmen Benedet en Oviedo, 22 de marzo de 2003.

75 Véase tarjetón exp. Antonio Saura. Pinturas, Oviedo, Galería Benedet, del 29 de octubre al 21 de noviembre de 1980.

76 Véase Barón, J., Exposiciones en Asturias durante 1982. Liño, 3, 632. El autor fue objeto de otra monográfica tres años más tarde. Véase tarjeta exp. Manuel Viola. Óleos, Oviedo, Galería Benedet, del 23 de abril al 17 de mayo de 1985.

77 Véase tarj. exp. Rafael Canogar. Óleos, Oviedo, Galería Benedet, del 5 al 28 de octubre de 1983.

78 Véase el tarjetón de la muestra Antoni Clavé. Pinturas y Gráfica, Oviedo, Galería Benedet, del 2 al 31 de octubre de 1985. Clavé repitió exposición en la sala en la década siguiente. Véase tarjetón exp. Antoni Clavé. Esculturas y Gráfica, Oviedo, Galería Benedet, del 22 de enero al 22 de febrero de 1991.

79 Véase tarjeta-díptico exp. Pablo Serrano. Esculturas, Oviedo, Galería Benedet, del 20 de noviembre de 1990 al 11 de enero de 1991. La muestra, dado el prestigio del expositor, contó con una protección extra a cargo de Seguridad Treinta y Ocho, S.A.

80 Véase tarjetón exp. Amadeo Gabino y Dario Villalba. Escultura, Gráfica y Pintura, Oviedo, Galería Benedet, del 26 de febrero al 5 de abril de 1991. 
con Darío Villalba, así como de las pinturas de Salvador Victoria ${ }^{81}$ (Rubielos de Mora, Teruel, 1928-Alcalá de Henares, 1994). No faltó tampoco un tributo a Ignacio Yraola ${ }^{82}$.

En los años finales de la galería los artistas asturianos encontraron otros cauces para exponer sus trabajos, dada la creciente oferta de establecimientos existentes en Oviedo y Gijón.

La galerista presentó de forma habitual el trabajo de destacados artistas, muchas veces a través de muestras colectivas del fondo de galería. Entre éstos destacó la presencia de Cuixart, Chillida, Chirino, Dau al Set, Equipo Crónica, Luis Gordillo, Roberto Matta, Plessi, Hernández Pijuán, Pablo Serrano, Rueda, Zush, Caballero, Canogar, Farreras, Feito, Genovés, Millares, Mompó, Navarro Baldeweg, Palazuelo, Picasso, Ponç, Quetglas, Ràfols-Casamada, Rivera, Saura, Sempere, Tharrats, Teixidor, Torner, Vasareli, Viladecans e Yraola.

\section{Publicaciones y acción cultural. El archivo de arte contemporáneo}

En muy pocas ocasiones, la galería estampó algo más que un simple y blanco tarjetón de papel Guarro, en que se indicaban los datos precisos y necesarios bien aclarados. Excepcionalmente, Benedet editó algunos folletos o dípticos.

Fue destacada la función pedagógica y educadora llevada a cabo por la galerista mediante la puesta en marcha de visitas escolares a sus exposiciones. Ya en 1965 organizaba talleres para estudiantes en la sala ${ }^{83}$.

Respecto a la acción cultural y social, preparó exposiciones de carácter benéfico y además se preocupó de explicar de forma documentada y didáctica las novedades que introducía en la programación de la sala. Al mismo tiempo, colaboró en la preparación de charlas, conferencias, conciertos y otros encuentros, celebrados a veces en otros foros de la ciudad, dadas las condiciones espaciales de la galería. La censura no impidió la exitosa representación de algunas obras de teatro de compromiso, como El cepillo de dientes (1961), que Jorge Díaz (Rosario, Argentina, 1930- Chile, 2007) escenificó en la papelería. En 1970, la galerista presentó una exposición de dibujos y móviles de Jorge Díaz y Luis Ipinza que incluyó además la lectura de obras de teatro originales del primero ${ }^{84}$.

Antes de que Carmen Benedet iniciara su actividad, ésta comenzó a reunir toda la documentación posible sobre arte contemporáneo y especialmente acerca de las últimas tendencias, lo que derivó en un singular archivo, aún conservado y de enorme importancia ${ }^{85}$. El primer domicilio del fondo documental fue el despacho contiguo a la galería ${ }^{86}$.

81 Véase tarjeta exp. Salvador Victoria. Pintura, Oviedo, Galería Benedet, del 6 al 28 de octubre de 1993.

82 Véase tarjeta Exposición Homenaje a Ignacio Yraola. Pinturas, Oviedo, Galería Benedet, del 15 de diciembre de 1992 al 14 de enero de 1993.

83 Datos obtenidos durante la entrevista mantenida con Carmen Benedet en Oviedo el 22 de Marzo de 2003.

84 Véase tarjetón exp. Dibujos y móviles de Jorge Díaz y Luis Ipinza, Oviedo, Galería Benedet, del 18 al 25 de marzo de 1970 .

85 El archivo de arte contemporáneo es el único elemento sobreviviente de los que conformaron la dedicación profesional de Carmen Benedet. Sobre este conjunto documental véanse nuestros trabajos: Aparicio Vega, J.C. (2012). El archivo de arte contemporáneo Benedet. Oviedo, 1960-2011. Liño. Revista Anual de Historia del Arte, 18, 121-130; Aparicio Vega, J.C. (2013). Los archivos privados de arte en Asturias. El caso de la galerista Carmen Benedet. En González Cachafeiro, J. (Ed.), Actas $5^{a}$ S Jornadas Archivando: Los archivos privados. León: Fundación Sierra Pambley, 98-106.

86 El archivo está actualmente en un local de unos 70 metros cuadrados próximo al nuevo domicilio de la galerista en Oviedo. 


\section{La red de relaciones profesionales de Benedet}

Carmen Benedet conoció entre 1960 y $1964^{87}$ a muchos artistas en las salas Abril y Neblí, donde aprendió las técnicas de embalaje, colgado, iluminación y entabló relación con críticos y clientes; en suma, se familiarizó con una profesión que aún se iniciaba en Madrid.

Antonio Suárez ${ }^{88}$ presentó a Carmen Benedet y a Juana Mordó en 1965 en la galería de la madrileña y ésta le cede la representación de Suárez para Oviedo. Así, la galerista fue "amiga y discípula de Juana Mordó» ${ }^{89}$, que movía a sus artistas entre las salas a las que estaba asociada, actuando como centro distribuidora de las nuevas tendencias artísticas desde Madrid en algunas provincias donde encontró aliados.

Juana Mordó ${ }^{90}$, de origen griego, pero nacionalizada francesa ${ }^{91}$, abrió su galería en la calle Villanueva de Madrid en $1964^{92}$ tras finalizar su etapa como directora artística de la sala de Aurelio Biosca entre 1958 y 1963, lo que también supuso un nuevo ciclo en la línea de la empresa del catalán ${ }^{93}$. Por tanto, Mordó abrió su propio negocio con más de sesenta años ${ }^{94} \mathrm{y}$ fue todo un referente, aunque no el único para la asturiana, que recibió ${ }^{95}$ tanto a sus artistas como sus exposiciones. De este modo, contribuyó a que la modernidad llegara a otras ciudades españolas, como en el caso de la firma sevillana La Pasarela ${ }^{96}$.

En la sala ovetense se reflejó de forma clara el selecto grupo de expositores de la griega entre los que despuntaban Millares, Mompó, Guerrero, Saura, Carmen Laffón, Zóbel, Lucio Muñoz, Julio López Hernández, Chirino, Rueda, Salvador Victoria, Sempere, Torner, Manuel Rivera, Canogar y Feito ${ }^{97}$.

87 Datos obtenidos durante la entrevista mantenida con Carmen Benedet en Oviedo el 22 de Marzo de 2003.

88 Véase tarjeta exp. Pinturas de Antonio Suárez, Madrid, Galería Juana Mordó, desde el 5 de abril de 1965.

89 Véase Rubén Suárez, Galerías con nombre propio. De los 30 años de Carmen Benedet al proyecto de futuro de Luis Aurelio Sánchez. La Nueva España, Oviedo, 15 de octubre de 1994.

90 Juana Mordó nació el 26 de abril de 1899 en Salónica. Era hija de León Naar. Se casó en París con Albert Yacoel y en Berlín, ya separada, conoció a Henri Mordó. Enviudó en 1942 y al año siguiente ya estaba en España, llegando a ser muy célebre su domicilio de la calle Rodríguez San Pedro por sus tertulias y reuniones. En 1958 entra en Biosca, donde permanece cinco años. El 14 de marzo de 1964 abrió su propia galería en el núm. 7 de Villanueva, en pleno barrio de Salamanca. Entre 1975 y 1980 habilitó otro local complementario en Castelló 7 conjuntamente con Manuel Mendoza inaugurado con una muestra de Manuel Rivera.

Antolín confirma en su nota de prensa la llegada de Mordó a España en 1943. Enriqueta Antolín. La galería Juana Mordó cierra a los 10 años de la muerte de su creadora. El País, Madrid, 19 de enero de 1995.

La apertura de la galería fue una de los hechos más significativos de esta década artística en Madrid. Véase Bonet, J. M. (1990). Una década complicada. En cat. exp. Madrid. El Arte de los 60. Madrid: Comunidad de Madrid, 109.

91 Información facilitada por Carmen Benedet el 21 de febrero de 2006.

92 El País, Madrid, 13 de Marzo de 1984.

93 Véase Calvo Serraller, F. (1992). op. cit.72-73.

94 Información obtenida durante la entrevista al galerista Leandro Navarro Ungría en Madrid el 13 de marzo de 2006.

95 Todos los acuerdos contractuales entre ambas galeristas se realizaron verbalmente, por lo que no contamos con documentación al respecto.

96 El investigador Genaro Marcos destaca en su estudio la ayuda de Juana Mordó respecto a la galería La Pasarela, abierta también en los años sesenta. Véase J. Félix Machuca. Un estudio sobre las galerías sevillanas constata que en el Ayuntamiento no se tipifica la cualificación de esta industria. $A B C$, Sevilla, 10 de diciembre de $1987,41$.

97 Juan Manuel Bonet, Juana Mordó: Adiós a una época. ABC Cultural, 146, 19 de agosto de 1994, 22. 
Mordó falleció en marzo de $1984^{98}$, pero la sociedad continuó operando ${ }^{99}$. La sucesora y última socia de Mordó, Helga de Alvear entró en la sala en $1980^{100}$ y en $1994^{101}$ decidió cerrar la prestigiosa galería madrileña y abrir la suya propia en la calle Doctor Fourquet ${ }^{102}$. La sala de Villanueva 7 fue reabierta por Margarita Summers ${ }^{103}$ en 1995.

Benedet formó parte del grupo intergeneracional de las pioneras galeristas de arte contemporáneo surgidas en el Madrid de los años cincuenta y sesenta. En su círculo estaban Carmen Abril, Amparo Martí, Loli ${ }^{104}$ y Pepi Sánchez, Margarita de Lucas ${ }^{105}$ y Juana Mordó y se incorporarían igualmente Elvira González ${ }^{106}$, Fefa Seiquer ${ }^{107}$, Eugenia Niño ${ }^{108}$, Gloria Kirby ${ }^{109}$, Enrique Menor y Amparo Barberó-Ferrándiz ${ }^{110}$,

98 Véase «Juana Mordó murió ayer en Madrid», en Diario 16, Madrid, 13 de marzo de 1984, 26. Noticia procedente del Archivo de Antonio Suárez (ejemplar duplicado conservado en el Museo Jovellanos de Gijón). Véase también la necrológica publicada en El País, Madrid, 13 de marzo de 1984.

99 Véase tarjeta exp. Karin Sander, Madrid, Galería Juana Mordó, desde el 26 de mayo de 1994.

100 Calvo Serraller, F. (1992). op. cit., 243.

101 En 1989 Helga había dejado la galería y tras ella Armando Montesinos ejerció como director artístico de la sala, orientándola hacia nuevos caminos.

Se recoge el cierre del local en Enriqueta Antolín. op. cit.

102 Juan Manuel Bonet. Juana Mordó: Adiós a una época, art. cit., 22.

103 Adolfo Castaño, El reto de una generación. ABC Cultural, 209, 3 de noviembre de 1995, 27.

104 Loli Sánchez trabajó en la galería Neblí. Información de Carmen Benedet facilitada el 23 de agosto de 2008.

105 El año 1964 también abre en Madrid la galería Edurne, dirigida por Margarita de Lucas y Antonio Navascués, con una línea de trabajo claramente orientada a la creación contemporánea. Véase Calvo Serraller, F. (1992). op. cit., 135.

106 La Galería Theo era una sociedad anónima con sede en el número 27 de la calle Enrique Granados y también en la plaza del Doctor Letamendi 1 y 2 de Barcelona [Información procedente del archivo Benedet]. Estaba ubicada en el núm. 2 de la calle Marqués de la Ensenada. Abrió sedes en Valencia (1970) y Barcelona (1975). Desde 1966 la empresa estaba dirigida por Elvira González y su esposo el pintor y miembro fundador del Grupo Hondo Fernando Mignoni Monticelli (Madrid, 1929-2011). Además tuvo un local especializado en obra gráfica denominado Theografic, abierto en el antiguo espacio de la Sala Celini. En 1989 se habilitó un nuevo local, Theo Espacio en la calle Eduardo Dato.

Véanse: Calvo Serraller, F. (1992). op. cit., 408; Francisco Calvo Serraller. Obituario: In Memóriam. Fernando Mignoni, pintor y galerista. El Pais, Madrid, 5 de febrero de 2011; Necrológicas. Últimos fallecimientos en el mundo del arte: Fernando Mignoni. En http: //www.arteinformado, 9 de febrero de 2011.

107 María Josefa Martínez Seiquer (Madrid, 1917-2009), fallecida el 2 de mayo de 2009, fue una de las galeristas pioneras en el Madrid de los años sesenta y mantuvo una estrecha amistad con Carmen Benedet. Abrió varios locales bajo su marca dedicados a la venta de arte contemporáneo. La primera galería Seiquer fue fundada en 1966. Véanse: Fallecen Fefa Seiquer y Miguel Logroño. En http: //www.arteinformado, 6 de Mayo de 2009; Juan Bordes. Fefa Seiquer, una galerista con pasión. El País, Madrid, 7 de mayo de 2009.

Estaba situada en el núm. 12 de la calle General Arrando. Véanse: Calvo Serraller, F. (1992). op. cit., 396; Blanca Sánchez Berciano. Fefa Seiquer. Galerista. En http: //www.e-leusis.net/cultura/Fefa.htm, 22 de mayo de 2006; Sánchez Berciano, B. y Gómez de Liaño, I. (1999). Fefa Seiquer. Madrid: Círculo de Bellas Artes.

108 La caraqueña Eugenia Niño Passios fundó la galería Sen, con sede en Núñez de Balboa en el año 1969. Desde 1993, la sala tiene su domicilio en la calle Barquillo de Madrid, siendo codirigida por Eugenia y su hijo Álvaro de Suñer. Véase Eugenia Niño, a punto de cumplir 40 años con galería Sen. En http: //www.arteinformado.com, 13 de Abril de 2008. En mayo de 2009 este histórico establecimiento finalizó su actividad comercial. Véanse: Cierra la madrileña Galería Sen. En http: //www.arteinformado.com, 28 de Mayo de 2009; Calvo Serraller, F. (1992). op. cit., 396-397. Carmen Benedet aún mantuvo un activo contacto con Niño, de la que destaca su importante taller de gráfica. Además, según la galerista ovetense, facilitaron estancias temporales de artistas jóvenes en residencia para lo que contaban con un apartamento-estudio.

109 Kirby era la dueña de la galería Vandrés. Información de Mariví Otero durante la entrevista mantenida en la galería Meriem Mezian de Madrid el 10 de marzo de 2006.

110 Benedet trabajó con la galería Múltiple 4.17 (luego 4.17), a cargo de Enrique Menor, domiciliada en Príncipe Vergara 17 de Madrid, que había sido fundada por Amparo Barberó-Ferrándiz en 1973 y estaba especializada en escultura contemporánea. Véase Calvo Serraller, F. (1992). op. cit., 125. Barberó y Menor surtían a la ovetense de esculturas múltiples para lo que contaban con una fundición. 


\section{Antonio Machón, Carmen Durango, Enrique Gómez Acebo ${ }^{111}$ y María Corral López- Dóriga, entre otros.}

Carmen Benedet tuvo otros modelos que no debemos dejar de tener en cuenta: Abril y Neblí, dos de las empresas donde se había formado en los aspectos prácticos que atañen al funcionamiento de un establecimiento de estas características y que completaban los conocimientos adquiridos en la Escuela Profesional de Comercio ovetense y en el negocio familiar. Por tanto, Carmen Benedet se relacionó con destacadas figuras del galenismo madrileño ${ }^{112}$ de aquel momento, entre las que sobresalen principalmente a Carmina Abril ${ }^{113}$ y Amparo Martí1 ${ }^{114}$. Curiosamente la sala Neblí contradecía ${ }^{115}$ el discurso plástico de Mordó-Benedet, que apostaban por los artistas informalistas.

Benedet destinaba regularmente un presupuesto para viajes en los que se contactaba directamente con los galeristas garantizando así depósitos de calidad. Si bien trató con muchos establecimientos, son destacables las relaciones mantenidas con Maeght-Barcelona, Gaspar, Grupo Quince, Polígrafa y Juana Mordó

111 La galería Egam se fundó en 1969, a cargo de Enrique Gómez Acebo. Situada en la calle Villanueva de Madrid. Véase Francisco Carpio. Cumpleaños feliz. Blanco y Negro Cultural, 646, 12 de junio de 2004, 28.

112 Siempre atenta al devenir del arte de su tiempo, buscó interrelacionarse desde 1960 con aquellas empresas y personalidades que estaban vinculadas a la vanguardia, escasas en el paupérrimo contexto español de ese momento. No le interesaban las galerías más conservadoras y en ese momento Biosca exponía a la Escuela de Vallecas. Información facilitada por Carmen Benedet el 18 de diciembre de 2004.

113 Carmina Abril era en realidad Carmen Díaz Herrero. Información facilitada por Carmen Benedet el 18 de diciembre de 2004.

La ovetense Carmen Abril falleció el 11 de octubre de 1985 en Madrid, ciudad a la que había llegado muy joven y donde abre la librería-galería Abril al comenzar la década de los años cincuenta. Antes, trabajó en otras librerías, como Doña Pepita y Afrodisio Aguado. Su espacio tuvo una orientación inicial muy marcada por la poesía, el teatro y el arte. Expuso a un joven Barjola y a Gerardo Rueda entre otros. Lo más importante era su tertulia semanal. Véase Javier Rubio, Ha muerto Carmina Abril, algo más que una galería. $A B C$, Madrid, 17 de octubre de 1985, 53. Información procedente del Archivo Benedet, sobre Galería Abril.

La sala abrió sus puertas en 1950, cuando Tomás Seral le vende el local de Clan a Carmina Abril, quien también añade al negocio de venta de libros una moderna sala de arte. En mayo de 1986, la propia Galería Abril acogió una muestra de una veintena de artistas-amigos de la promotora. Véanse: Calvo Serraller, F. (1992). op. cit., 109; Fernández Polanco, A. (1988). op. cit., 14; Homenaje a Carmina Abril. ABC, Madrid, 8 de mayo de $1986,114$. La galería Abril contaba con un mural de Luis Castellanos (Madrid, 1915-1946), que se quemó posteriormente. Información de Mariví Otero durante la entrevista mantenida en la galería Meriem Mezian de Madrid el 10 de marzo de 2006.

114 Neblí se encontraba desde 1958 en el número 80 de la calle Serrano de Madrid. El moderno local en que se encontraba fue pensado por el arquitecto J. López Asiáin.

La dirección de la sala manifestó que «una galería de arte...debe seguir una línea estética claramente definida... En una galería de arte se presenta lo más nuevo, aquello que está formando y conformando lo que llamamos arte vivo... Dar a conocer, difundir, acreditar, son objetivos iniciales de la Galería». Defiende una función informativa y formativa de la galería de arte. Véase Amparo Martí. Artistas exclusivos. Folleto Informativo, Madrid, Sala Neblí, s.f.

Las hermanas Loli y Pepi Sánchez trabajaron en la galería (la primera de ellas era la encargada de la sala) y Amparo Martí Tío fue la directora. Información de Carmen Benedet completada con la propia tarjeta de visita de ésta, adjuntada a la carta dirigida por Dolores Sánchez a Carmen Benedet, fechada en Madrid a 10 de noviembre de 1966. Archivo Benedet, sobre Galería Neblí.

María Dolores Sánchez llevó la galería Cultart de Madrid. Información contenida en la carta que el artista Cayetano Crespo dirige a Carmen Benedet y fechada en Madrid a 15 de septiembre de 1971. Archivo Benedet, sobre Galería Neblí..

115 Véase impreso exp. César Arias/Francisco Cruz de Castro/Francisco Molina/Ceferino Moreno/Manuel Gómez Raba/Amador Rodríguez/ Ignacio Yraola, Madrid, Sala Neblí, del 23 de febrero al 9 de marzo de ? En este folleto la dirección de la galería habla de que «Después de la proliferación de artistas informalistas se ha producido una crisis en el panorama plástico más reciente...La Galería Neblí se ha propuesto con esta Exposición proporcionar un nuevo punto de apoyo para una revisión del momento actual de la pintura». 
que le abastecieron de fondos de arte y editoriales para su venta en Oviedo. Por tanto, sus visitas eran realmente una inversión y, sobre todo, la expresión de un permanente interés por estar al día y por formar parte activa del circuito nacional de los galeristas españoles en un período en que las ferias de arte no eran el cauce para estar al día.

Hubo incluso relaciones profesionales de Carmen Benedet con la familia Gaspar $^{116}$, poseedora de una de las galerías más reputada del país ${ }^{117}$. Por otra parte, Benedet tuvo trato comercial con otros prestigiosos establecimientos, como Polígrafa ${ }^{118}$, donde la galerista ovetense compró libros y obra gráfica.

Benedet comercializó excepcionales ediciones de la galerista vallisoletana Carmen Durango, cuyo establecimiento fundado en $1973^{119}$ estuvo dirigido en un principio por Antonio Machón ${ }^{120}$.

\section{Relación con los medios. Comisiones de venta. Ferias de arte}

Por otra parte, Carmen Benedet asesoró a otros galeristas asturianos y cedió exposiciones a varios espacios institucionales. Sin embargo, tuvo que trabajar con una escasa repercusión ${ }^{121}$ de sus actividades en los medios de comunicación escrita locales, algo que mejoraría sobre todo a partir de la década de los años setenta.

Respecto a las comisiones que cobraba a los artistas, Benedet aplicaba un $20 \%$, que con el tiempo subió hasta el 30\% del importe de la venta ${ }^{122}$.

Así mismo, la sala ovetense fue la primera de la provincia en concurrir a una feria de arte en fecha temprana. En 1976 Carmen Benedet participó en Artexpo de Barcelona, invitada por Juana Mordó, quien le cedió temporalmente la representación de Rinaldo Paluzzi, que estuvo acompañado de los trabajos de Orlando Pelayo, Trinidad Fernández y Antonio Suárez ${ }^{123}$. Aun con ayuda profesional y económica y vendiendo toda la obra expuesta, Carmen Benedet, que no cobró a los artistas representados, no llegó a cubrir gastos, lo que motivó que no volviese a concurrir a las ferias de arte.

116 Ubicada muy próxima a Dalmau, en el núm. 323 de Consejo de Ciento, Gaspar fue fundada en 1909, aunque la sala de exposiciones data de 1927.Véase Calvo Serraller, F. (1992). op. cit., 382-283.

Gaspar era el único marchante en España con poder notarial para extender certificados (fotográficos) de autentificación para la obra de Picasso. Información facilitada por Carmen Benedet el 18 de agosto de 2008. Benedet conserva en su biblioteca los catálogos de la obra gráfica de Picasso, adquiridos en Ginebra [Bloch, G. (19721979). Pablo Picasso. Catalogue de l'oeuvre grave et lithographie. Berne: Kornfeld et Klipstein].

117 Información corroborada por Joan Gaspar el 12 de agosto de 2008.

118 Este dato fue confirmado por el director de Ediciones Polígrafa Ángel Samblancat el 9 de octubre de 2008.

11 Calvo Serraller, F. (1992). op. cit., 90-91.

120 Antonio Machón en 1983 fundó su propio establecimiento en Madrid. Véase http: //www.antoniomachon.com/ galeria_historia.asp [Consulta: 3 de marzo de 2009].

121 Véase el reducidísimo anuncio de clausura de la exposición de Fernando Sáez en febrero de 1968 que aparece en el diario La Nueva España (15 de febrero de 1968, 8).

122 Información facilitada por Carmen Benedet el 3 de abril de 2008. La comisión inicial aparece recogida en la prensa con motivo de la apertura de la sala. Véase Manuel Perujo. op. cit.

123 Véase tarjetón exp. Artexpo'76, Galería Benedet, Barcelona, del 6 al 14 de noviembre de 1976. 


\section{Conclusiones}

A lo largo de este artículo se ha tratado de perfilar la personalidad de la galerista Carmen Benedet y su modo de proceder en el panorama del comercio artístico español en el que se insertó de forma muy activa a partir de 1964. Por lo metódico de su trabajo y por haber marcado una línea claramente comprometida con el arte contemporáneo, además de por haber sabido conformar una entreverada y cuidada red de relaciones con los protagonistas del sector, liderados por Juana Mordó, pudo nutrirse de obra de calidad y evitar así que, a pesar de su plaza periférica en Oviedo, los artistas asturianos acapararan la programación. Fue determinante la localización del espacio expositivo en el centro de una ciudad concentrada en sí misma y su cercanía al moderno y activo local de la Obra Social y Cultural de la Caja de Ahorros Provincial, abierto a la plaza de la Escandalera en 1956. Por último, sería fundamental su etapa formativa en varias galerías de Madrid al inicio de la década de los años sesenta, que implementó de forma continuada y acompañó de la creación y organización de un archivo especializado.

Benedet sumó a su formación y experiencia comercial, aprehendida en el seno familiar, su segura y decidida idea de implantar en Oviedo un modelo de galería para lo que no dudó en alternar estancias en Madrid en busca de modelos válidos y sostenibles que implantar en su local. El resultado es uno de los ejemplos más claros de galería consecuentes con su tiempo que hubo en Asturias. No mostró una actitud dubitativa ni complaciente. Además, supo adaptarse a las limitadas condiciones y necesidades del contexto local. Su programación se centró principalmente en presentar la actualidad de los artistas que protagonizaban el circuito madrileño. Por otra parte, en su tienda se comercializó una ingente cantidad de obra, principalmente gráfica dado que su menor coste hacía posible el incremento de las ventas. Esta especialización en estampas de gran calidad pero poco atendidas por los museos de los años setenta y ochenta, hizo que por lo general éstos no adquiriesen obra de sus expositores y que Benedet se interrelacionase en mayor medida con el pequeño coleccionista burgués al que contribuyó a educar y formar.

La opacidad generalizada y la ausencia, hasta la fecha, de archivos y datos contables (negados a los investigadores), así como la inexistencia de documentación referida a la gestión de las exposiciones (la mayor parte de las operaciones se cerraban por teléfono e intercambio de albaranes), inclusive en el caso de las principales firmas, hace que el mero hecho de la durabilidad del negocio, algo evidente en el caso de Benedet, cuyo cierre tras tres décadas y media tuvo lugar en 1999, y la invariabilidad en su línea de expositores sean prueba irrefutable de su aportación al circuito local y nacional. 


\section{Fuentes documentales.}

Archivo Benedet, Oviedo.

Centro de Documentación Antonio Martín, Museo Casa Natal de Jovellanos, Gijón: Fondo Patricio Adúriz. Carp ${ }^{a}$ Manuel Medina Díaz, Fondo Antonio Martín y Fondo Antonio Suárez

Biblioteca MNCARS, Museo Nacional Centro de Arte Reina Sofía, Madrid: Material especial/5/Benedet.

AMO, Archivo Municipal de Oviedo. Exptes.: Doc. 13. 926; 1,1, 4, 73; 1,1, 4,74; 1,1, 4, 76; B-2377/64.

A.H.A., Archivo Histórico de Asturias, Fondo Diputación Provincial. Expte: 2617/40, documento 52.

Archivo de El Museo Canario, Fondo Documental Galería Wiot. 